\title{
Diagnosis and Surgical Management of Cholecystolithiasis in Two Adult Inland Bearded Dragons (Pogona vitticeps)
}

Hanae Pouillevet ${ }^{1}$, Dr med vet, IPSAV (Zoological Medicine), Jessica Aymen², DVM, IPSAV (Zoological Medicine), Cédric B. Larouche², DVM, IPSAV (Zoological Medicine), DVSc, DACZM, Pauline Delnatte ${ }^{2}$, Dr med vet, IPSAV (Zoological Medicine), DVSc, DACZM, DECZM (Zoo Health Management), Claire Louvard' ', Dr med vet iPSAV, Stéphane Lair ${ }^{3}$, DVM, DES, DVSc, DACZM, Isabelle Masseau ${ }^{3}$, DVM, PhD, DACVR, Claire Vergneau-Grosset ${ }^{3}$, Dr med vet, IPSAV (Zoological Medicine), CES, DACZM

' Centre Hospitalier Universitaire Vétérinaire, Université de Montréal, 3200 rue Sicotte, Saint-Hyacinthe, QC, J2S2 M2, Canada

2 Toronto Zoo, 361A Old Finch Avenue, Scarborough, ON, M1B 5K7, Canada

${ }^{3}$ Département de Sciences Cliniques, Faculté de médecine vétérinaire, Université de Montréal, 3200 rue Sicotte, SaintHyacinthe, QC, J2S2 M2, Canada

\begin{abstract}
Two male inland bearded dragons (Pogona vitticeps) of 5 and $6 \mathrm{yr}$ of age were presented for anorexia with and without lethargy, respectively. In both cases, a firm, spherical, and mobile mass, measuring 2 $\mathrm{cm}$ in diameter, was palpated in the cranio-medial coelom. Radiographs were unremarkable. Ultrasonographic evaluation was highly suggestive of cholecystolithiasis. Coeliotomy confirmed the presence of a markedly enlarged gallbladder containing a cholecystolith in both cases, and cholecystectomies were performed. Both dragons resumed eating after 1-7 days and were doing well 3-6 months postoperatively. The gallbladder wall was unremarkable on histology, and the choleliths were composed of protein and calcium carbonate crystals. Cholecystolithiasis in bearded dragons has been the subject of very few case reports, probably due to its low occurrence. The lack of available data on the diagnosis and management may have led to this condition being underdiagnosed in this species. Ultrasonography was essential to the clinical diagnosis of cholecystolithiasis in our two cases and should be recommended as part of the diagnostic approach of bearded dragons with cranio-medial coelomic masses.
\end{abstract}

Key Words: Pogona vitticeps, cholecystectomy, gallstone, lizard, nutrition, surgery

\section{Introduction}

In lizards, the gallbladder is attached to the right caudal pole of the liver and conveys bile from the liver to the duodenum via a cystic duct (Hernandez-Divers and Cooper, 2005). Bile is stored in the gallbladder and plays important roles in the digestion, absorption, and excretion of fat (Haslewood, 1967). In inland bearded dragons (Pogona vitticeps), the gallbladder is easily identified on ultrasonography as a thin-walled, round structure on the right caudal border of the liver (Bucy et al., 2015). In a study of 42 healthy bearded dragons, the median longitudinal and transverse diameters of the gallbladder were 1.05 $\mathrm{cm}$ (range: $0.43-2.04 \mathrm{~cm}$ ) and $0.56 \mathrm{~cm}$ (range: $0.23-1.40$ $\mathrm{cm}$ ), respectively (Wachsmann, 2010). The gallbladder content varies from strictly anechoic (Wachsmann, 2010; Bucy et al., 2015) to anechoic with well-formed intraluminal debris or dependent sediment (Bucy et al., 2015).

Postmortem evaluation was necessary to identify irregular gallbladder contents such as sludge and choleliths in eight of nine adult bearded dragons in a previous study, whereas the antemortem sonographic evaluation revealed a gallbladder cholelith in only one individual (Gimmel et al., 2017). Cholecystolith was present in 6 of 9 cases, sludge in 3 of 9 cases, and both cholecystolith and sludge in 1 of 9 cases. In these cases, composition of the gallbladder content was variable, including calcium carbonate and protein-based material. Wild bearded dragons are reported 
as requiring a balanced insectivorous and herbivorous diet (Oonincx et al., 2015); thus, a high-protein, high-fat insectbased captive diet was hypothesized to be a predisposing factor in these cases. In reptiles, known etiological causes of choleliths include metazoan (trematodes) and protozoan (e.g., Hexamita, Choleoeimeria, Trichomonas) parasitic infections, probably due to migration from the gastrointestinal tract (Divers, 2019).

Information on the diagnosis and treatment of cholelithiasis, and in particular cholecystolithiasis, in lizards is scarce. Surgical removal of choleliths has been reported in three adult bearded dragons who subsequently successfully recovered (Ritzman and Garner, 2009; Gimmel et al., 2017). However, in these cases, the surgical procedure was not thoroughly described. The purpose of this case series is to supplement the sparse literature on cholecystolithiasis in adult bearded dragons with the diagnostic process and surgical management by total cholecystectomy of two inland bearded dragons with successful outcomes.

\section{Case Series}

Clinical report 1: A 5-yr-old male inland bearded dragon presented to the Service de médecine zoologique of the Centre Hospitalier Universitaire Vétérinaire with a 4-day history of anorexia after 2 wk of dysorexia. The inland bearded dragon was housed in an exhibit $(80 \mathrm{~cm} \times 44 \mathrm{~cm})$ with a temperature variation of $24-32^{\circ} \mathrm{C}\left(75.2-89.6^{\circ} \mathrm{F}\right)$, measured at the level of the animal. Humidity in the exhibit was not monitored. The diet was composed of calcium/ multivitamins-supplemented (Repti Calcium ${ }^{\circledR}$ without D3, Zoo Med Laboratories, San Luis Obispo, CA, USA; Rep$\mathrm{Cal}^{\circledR}$, Research Labs, Los Gatos, CA, USA) arugula salad ( $80 \%$ of the diet), mixed vegetables $(15 \%)$, and frozenthawed crickets $(5 \%)$. On physical examination, an approximately 2-cm-diameter, firm, spherical, mobile mass was palpated in the cranial coelom. The remainder of the physical examination was unremarkable. Differential diagnoses included digestive impaction (Mans, 2013); neoplasia, such as neuroendocrine gastric carcinoma/ somatostatinoma (Ritter et al., 2009) and gallbladder (Jakab et al., 2011) or hepatic (Griswold, 2001) neoplasms; and cholelithiasis (Gimmel et al., 2017). Dorsoventral and lateral whole-body radiography was unremarkable. Digestive impaction was considered unlikely based on the absence of gas in the intestines or lack of gastric distension.

Blood was collected from the ventral coccygeal vein, and glucose was measured using a portable blood glucose meter (AlphaTRAK ${ }^{\circledR}$ 2, Abbott Laboratories, North Chicago, IL, USA). Glucose concentration (19.9 mmol/L, $360 \mathrm{mg} / \mathrm{dl})$ was slightly increased compared with reference values for bearded dragons (7.72-16.2 mmol/L, 139-291 mg/dl [Ellman, 1997]; 12.10-19.76 mmol/L, 218-356 mg/dl, in males [Tamukai et al., 2011]; 5.99-18.48 mmol/L, 108-333 mg/dl [Klaphake et al., 2018]); however, it remained below described hyperglycemia reports in cases of somatostatinomas in this species (>49.6 mmol/L, $894 \mathrm{mg} / \mathrm{dl})$ (Ritter et al., 2009).

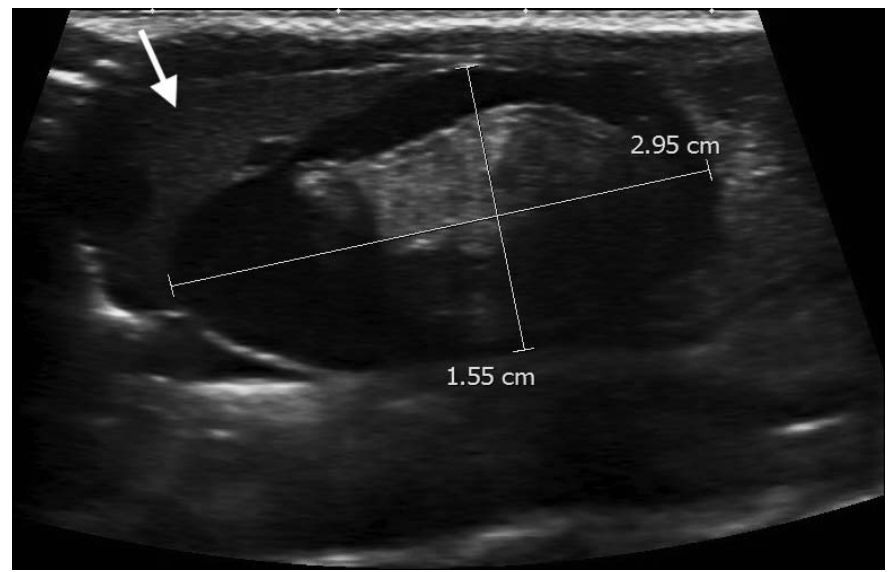

Figure 1. Ultrasonographic image of the gallbladder in a longitudinal plane containing a large cholelith in the inland bearded dragon (Pogona vitticeps) from clinical report 1 . The gallbladder is markedly distended, measuring $2.95 \mathrm{~cm}$ in length and $1.55 \mathrm{~cm}$ in height. The cholelith is characterized by a thick peripheral hypoechoic band surrounding an irregularly shaped hyperechoic center, and it occupies the entire lumen of the gallbladder. Cranial to the gallbladder, normal hepatic parenchyma can be observed (arrow). The ultrasonographic examination of the gallbladder was highly suggestive of cholecystolithiasis.

Ultrasonographic examination with a linear array transducer 13-18 MHz (ultrasound unit, Toshiba Aplio 400, Toshiba Medical, Markham, ON, Canada) was performed under sedation by using $3 \mathrm{mg} / \mathrm{kg}$ IM alfaxalone (Alfaxan ${ }^{\circledR}, 10 \mathrm{mg} / \mathrm{ml}$, Jurox Animal Health, Hunter Valley, NSW, Australia) in the triceps muscle. The coelomic mass $(1.55 \times 2.95 \mathrm{~cm})$ was characterized by a peripheral hypoechoic band surrounding a hyperechoic center in comparison with the adjacent, normal hepatic parenchyma echogenicity (Fig. 1). The ultrasonographic appearance of the markedly distended gallbladder was highly suggestive of cholecystolithiasis (Wachsmann, 2010; Bucy et al., 2015; Gimmel et al., 2017). Although cholecystostomy was considered, risk of recurrence and function of the gallbladder was questionable given the severe distension of the organ. Therefore, cholecystectomy was planned the following day.

Four hours before induction, the inland bearded dragon was injected with $1 \mathrm{mg} / \mathrm{kg}$ morphine (Morphine LP, Sandoz Canada, Boucherville, QC, Canada) (Sladky et al., 2008; Sladky and Mans, 2019), $20 \mathrm{mg} / \mathrm{kg}$ ampicillin (Novo-ampicillin, $250 \mathrm{mg}$, Novopharm, Toronto, ON, Canada), and $0.5 \mathrm{mg} / \mathrm{kg}$ vitamin $\mathrm{K}$ (Veda-K1 injection, 10 $\mathrm{mg} / \mathrm{ml}$ solution, Vedco, Saint-Joseph, MO, USA) (Klaphake et al., 2018). Vitamin $\mathrm{K}$ was administered to limit bleeding from the liver in case of hepatic tissue dissection (Grant and Neuberger, 1999). Induction was achieved using an injection of $4.5 \mathrm{mg} / \mathrm{kg}$ alfaxalone. All injections were administered IM in the forelimbs. Isoflurane $2 \%$ (Isoflurane, USP, Fresenius Kabi Animal Health, ON, Canada) was delivered in $100 \%$ oxygen via tight-fitted facemask 10 min later to allow for intubation. The glottis 


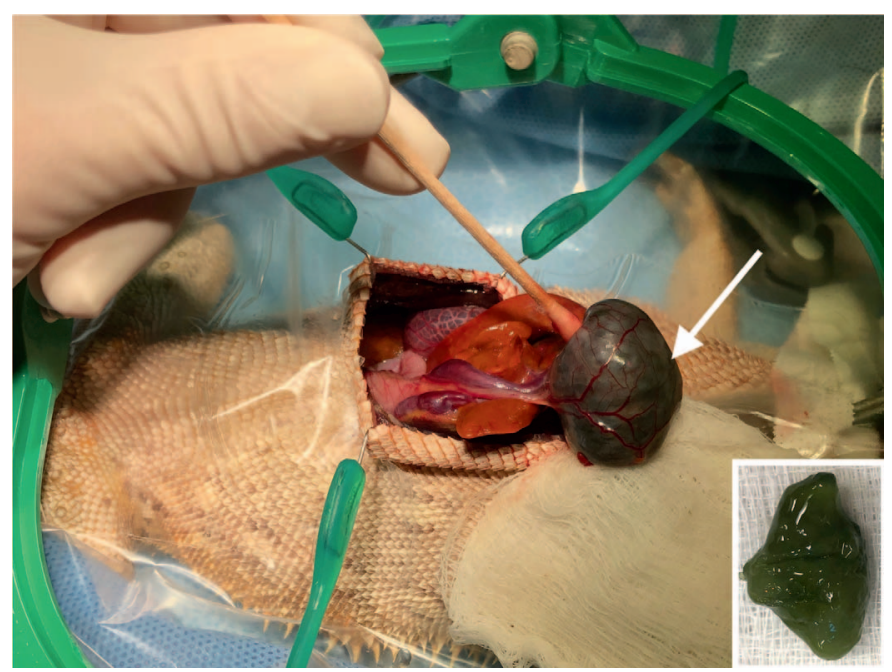

Figure 2. Perioperative photograph of the retracted distended gallbladder containing a large cholelith (bottom right) in the first inland bearded dragon (Pogona vitticeps) (clinical report 1). After paramedian incision, the skin was retracted (green retractors) revealing a markedly enlarged gallbladder (arrow) with prominent vasculature. A large and firm cholelith was palpable within the gallbladder.

was intubated using a 2-mm uncuffed endotracheal tube (Veterinary Specialty Products, Mission, KS, USA), and the isoflurane vaporizer was maintained at $2-3 \%$ in $100 \%$ oxygen with a $1-\mathrm{L} / \mathrm{min}$ flow throughout surgery. The lizard was placed in dorsal recumbency. A 24-gauge catheter (BD Insyte- $\mathrm{W}^{\mathrm{Tм}}$, Becton Dickinson Infusion Therapy Systems, Sandy, UT, USA) was placed into the ventral coccygeal vein and $5 \mathrm{ml} / \mathrm{kg} / \mathrm{h}$ of lactated Ringer's solution (Baxter Corporation, Mississauga, ON, Canada) was administered IV for the duration of surgery. Heart rate was monitored via a Doppler flow detector (ultrasonic Doppler flow detector, model 811-B, Parks Medical Electronics, Aloha, OR, USA) placed over the heart. Positive pressure-assisted ventilation was provided as needed, and the end-tidal concentration of carbon dioxide was monitored using a capnometer (Microcap ${ }^{\circledR}$ Plus, Oridion, Jerusalem, Israel). A cloacal thermometer was inserted and secured to the tail with adhesive bandage. Body temperature was maintained at approximately $33^{\circ} \mathrm{C}\left(91.4^{\circ} \mathrm{F}\right)$ during the procedure by using heating pads and an infrared lamp. The skin over the ventral coelom was aseptically prepared with alternating passages of two different concentrations of chlorhexidine solution (0.05 and 2\%). An injection of $2 \mathrm{mg} / \mathrm{kg} \mathrm{SC}$ lidocaine (Lurocaine ${ }^{\circledR}, 20 \mathrm{mg} / \mathrm{ml}$, Vétoquinol, Lavaltrie, QC, Canada) was administered along the incision site for local analgesia. A transparent adhesive drape was placed on the bearded dragon, and the coeliotomy was performed via an $8-\mathrm{cm}$ cranio-caudal paramedian incision by using a size 15 scalpel blade and iris scissors. The coelomic wall was retracted (Lone Star Retractor System, Lone Star Medical Products, Houston, TX, USA) while carefully avoiding the ventral abdominal vein. A markedly enlarged and firm gallbladder displacing the stomach was visualized (Fig. 2). Blunt dissection was performed with cotton tip applicators, bipolar electrocautery (Surgitron ${ }^{\mathrm{TM}}$, Ellman International, New York, NY, USA) and microsurgical scissors to progressively free the gallbladder from the liver. Moderate hemorrhage, estimated at $0.1 \mathrm{ml}$, occurred during the procedure. Consequently, the fluid rate of administration was temporarily increased to $10 \mathrm{ml} / \mathrm{kg} / \mathrm{h}$. Curved ophthalmic mosquito forceps were placed on the bleeding vessel at the base of the gallbladder, and two simple ligatures were placed at the base of the gallbladder using polydioxanone suture (PDS) material (PDS 3.0 and 4.0, Ethicon, Somerville, NJ, USA). Approximately $0.5 \mathrm{ml}$ of bile was aspirated using a 25-gauge needle attached to a 3-ml syringe to reduce the pressure inside the gallbladder. Hemostatic forceps were placed distally to both ligatures, and the bile duct and adjacent vessels were sectioned proximally to the forceps using iris scissors. The coelomic incision was closed in two layers. First, the muscular plane was sutured with cruciate stitches by using PDS 4.0 and then the skin was closed with nylon suture (Ethilon 4.0, Ethicon) in an everting horizontal mattress pattern while carefully avoiding the ventral midline abdominal vein. An injection of 0.2 $\mathrm{mg} / \mathrm{kg}$ meloxicam (Metacam ${ }^{\circledR}, 5 \mathrm{mg} / \mathrm{ml}$, BoehringerIngelheim, Burlington, ON, Canada) was administered SC at the end of the surgery. Recovery was uneventful and the lizard started moving within 30 min after discontinuing isoflurane. The intravenous catheter was removed when the patient started to move its limbs.

The bearded dragon was discharged the same day with $0.2 \mathrm{mg} / \mathrm{kg}$ meloxicam (Metacam ${ }^{\circledR}, 1.5 \mathrm{mg} / \mathrm{ml}$, BoehringerIngelheim, Burlington, ON, Canada) PO q $24 \mathrm{~h}$ for 5 days, $11 \mathrm{mg} / \mathrm{kg}$ tramadol (Tramadol, $50 \mathrm{mg} / \mathrm{ml}$, Summit Veterinary Pharmacy, Aurora, ON, Canada) PO q $24 \mathrm{~h}$ for 7 days, and $20 \mathrm{mg} / \mathrm{kg}$ amoxicillin-clavulanic acid (Clava$\operatorname{mox}^{\circledR}, 125 \mathrm{mg} / \mathrm{ml}$, Zoetis Canada, Kirkland, QC, Canada) PO q $12 \mathrm{~h}$ for 7 days. The bearded dragon resumed feeding by himself after 7 days. Meanwhile, he was stimulated to eat every day by its owner.

The excised gallbladder was sectioned in two parts: one part was frozen and other part was placed in 10\% buffered formaldehyde for histological evaluation. After 15 days, the fixed gallbladder tissue was embedded in paraffin; sectioned at $3 \mu \mathrm{m}$; stained with hematoxylin, phloxine, and saffron; and examined by light microscopy by one of the authors (SL). Edema and fibrosis of the gallbladder wall were noted. There were no evidence of cellular infiltration or infection of the gallbladder. Composition analysis on the frozen part of the cholelith was performed in the Diagnostics Unit of the Urolith Centre, University of Guelph, Guelph, ON, Canada. The cholelith was mainly composed of protein with calcium carbonate crystals and mineral salts. Upon receipt of the results, arugula salad was proscribed from the inland bearded dragon's diet and replaced by various vegetables, including non-Brassicaceae leaves such as romaine salad. The dragon was still doing well 7 months postoperatively.

Clinical report 2: A 6-yr-old male inland bearded dragon belonging to a zoo collection presented for lethargy and 
weight loss. The bearded dragon was housed in an exhibit $(120 \mathrm{~cm} \times 120 \mathrm{~cm})$ with a temperature variation of $24-37^{\circ} \mathrm{C}$ $\left(75.2-98.6^{\circ} \mathrm{F}\right)$, measured at the level of the animal. Humidity in the exhibit varied from 40 to $65 \%$, with a mean of $53 \%$. The diet was composed of calcium/ multivitamins-supplemented (Toronto Zoo Reptile Supplement, with vitamin D3, Scarborough, ON, Canada) mixed vegetables and greens ( $82 \%$ of the diet), live mealworms ( $8 \%$ of the diet), and live crickets (10\% of the diet). On physical examination, the inland bearded dragon had decreased fat stores and muscle mass, and an approximately 2-cm diameter, firm, spherical, mobile mass was palpated on midline in the cranial coelom. The remainder of physical examination was unremarkable. Radiographic and ultrasonographic findings were similar to the first clinical report, with the latter highly suggestive of cholecystolithiasis. Blood was collected from the ventral coccygeal vein and submitted for complete blood cell (CBC) count and biochemistry analysis, which were unremarkable. Polymerase chain reaction test performed from a cloacal swab yielded a positive result for Agamid Adenovirus 1 (Research Associates Laboratory, Allen, TX, USA). Oxyurid eggs visible on more than $80 \%$ of microscopic fields at $\times 100$ magnification were noted on fecal parasitology. The bearded dragon received a course of $100 \mathrm{mg} / \mathrm{kg}$ fenbendazole (Safe-Guard ${ }^{\circledR}, 100 \mathrm{mg} / \mathrm{ml}$, Intervet, Kirkland, QC, Canada) PO every 2 wk for three doses. Fecal parasitology was negative 5 and 7 wk after treatment initiation. The inland bearded dragon was moved to the Wildlife Health Centre to increase the animal's weight before surgery. A month later, a fourfold increase of the lymphocyte count (from $3.33 \times 10^{9}$ cells/L before fenbendazole treatment initially to $12.20 \times 10^{9}$ cells $/ \mathrm{L}$ ) was detected on the $\mathrm{CBC}$ and was interpreted as a slight lymphocytosis $\left(0.29-12.00 \times 10^{9}\right.$ cells/L) (Ellman, 1997). Recheck biochemistry was unremarkable. A course of 10 $\mathrm{mg} / \mathrm{kg}$ enrofloxacin (Baytril ${ }^{\circledR}, 50 \mathrm{mg} / \mathrm{ml}$, Bayer, Mississauga, ON, Canada) PO q $24 \mathrm{~h}$ for 14 days was initiated. The CBC was unremarkable $4 \mathrm{wk}$ after completion of treatment (including a lymphocyte count of $3.26 \times 10^{9} \mathrm{cells} / \mathrm{L}$ ). The patient was deemed fit for surgery once the weight stabilized after the antibiotic treatment.

Three hours before induction, the inland bearded dragon was premedicated with $2 \mathrm{mg} / \mathrm{kg}$ morphine, $0.5 \mathrm{mg} / \mathrm{kg}$ midazolam (Midazolam, $5 \mathrm{mg} / \mathrm{ml}$, Sandoz Canada), and 20 $\mathrm{mg} / \mathrm{kg}$ ampicillin IM. Anesthesia was induced with $15 \mathrm{mg} /$ $\mathrm{kg}$ alfaxalone IM, which allowed for endotracheal intubation with a 2-mm uncuffed endotracheal tube connected to a circle rebreathing system (Anesthesia WorkStation, Hallowell EMC, Pittsfield, MA, USA). All injections were administered IM in the forelimbs. The animal was maintained on 0.5 to $1 \%$ isoflurane delivered in a combination of $50 \%$ oxygen and $50 \%$ nitrous oxide with a combined gas flow of $0.4 \mathrm{~L} / \mathrm{min}$. The patient was mechanically ventilated throughout the procedure. An intraosseous catheter was placed in the right tibia to administer a balanced fluid solution $\left(\right.$ Normosol $^{\circledR}$ - R, Hospira, Inc., Lake Forest, IL, USA) at a rate of $5 \mathrm{ml} /$ $\mathrm{kg} / \mathrm{h}$. Heart rate was monitored using a Doppler flow detector placed over the heart. End-tidal carbon dioxide was monitored using a capnometer (Waveline Pro, DRE Inc., Louisville, KY, USA), and body temperature was monitored using a cloacal probe (Waveline Pro). Body temperature was maintained at approximately $31^{\circ} \mathrm{C}$ $\left(87.8^{\circ} \mathrm{F}\right)$ by using a heating surgical table and lamp. Surgical preparation and draping were performed as described in the first clinical report. Four centimeters caudally to the heart, a $5-\mathrm{cm}$ cranio-caudal paramedian incision was made using a size 15 scalpel blade and Metzenbaum scissors. Retraction of the coelomic wall was performed using Weitlaner retractors to enhance visualization of the gallbladder. A slightly opacified, fibrinous membrane covered the gallbladder and the ventral aspect of the liver, which was dissected using bipolar cautery. A markedly enlarged gallbladder was visualized. The gallbladder was adhered to the caudal aspect of the liver. Although cholecystostomy and stone removal were considered, complete cholecystectomy was elected based on thickening of the gallbladder wall and scant bile leakage noted upon opening of the coelom. A 30-gauge needle attached to a $3-\mathrm{ml}$ syringe was used to attempt cholecystocentesis, which yielded $0.2 \mathrm{ml}$ of bile and was unsuccessful in reducing the pressure inside the gallbladder. Smooth dissection was performed using cotton-tip applicators, bipolar electrocautery, and microsurgical scissors to progressively free the gallbladder from the liver. Numerous small liver fractures occurred due to the presence of marked adhesions. Absorbable gelatin sponge (Gel Foam, Pharmacia \& Upjohn, Pfizer, Kirkland, QC, Canada) was placed on fracture sites for hemostasis. Hemorrhage was estimated at $1 \mathrm{ml}$ throughout the surgery. A simple ligature with PDS 5.0 was placed at the base of the gallbladder, which included the major blood vessel. A second simple ligature was placed on a vessel branching off the main vessel at the base of the gallbladder. Hemostatic forceps were placed between the gallbladder and the ligatures before sectioning of the blood vessel and gallbladder. The coelomic cavity was rinsed with $40 \mathrm{ml}$ of isotonic saline $(0.9 \% \mathrm{NaCl}, \mathrm{B}$. Braun Medical Inc., Scarborough, ON, Canada) and then suctioned. The inland bearded dragon was ventilated with ambient air without isoflurane while closing the incision. The abdominal wall was sutured with a simple continuous suture pattern, and the epidermis was sutured with an everting horizontal mattress pattern, both using PDS 4.0. After abdominal wall closure, $1 \mathrm{mg} / \mathrm{kg}$ bupivacaine (Bupivacaine, $5 \mathrm{mg} / \mathrm{ml}$, Sterimax, Oakville, ON, Canada) was infiltrated between the abdominal wall and epidermis. Injections of $0.2 \mathrm{mg} / \mathrm{kg}$ meloxicam and 0.05 $\mathrm{mg} / \mathrm{kg}$ flumazenil (Flumazenil ${ }^{\circledR}, 0.1 \mathrm{mg} / \mathrm{ml}$, Sandoz Canada) were administered SC at the end of the surgery. Recovery was uneventful and the bearded dragon resumed feeding the following day. The inland bearded dragon received $0.2 \mathrm{mg} / \mathrm{kg}$ meloxicam $\mathrm{PO} \mathrm{q} 24 \mathrm{~h}$ for 10 days, $2 \mathrm{mg} /$ $\mathrm{kg}$ morphine SC q $24 \mathrm{~h}$ for 3 days, and $20 \mathrm{mg} / \mathrm{kg}$ ceftazidime (Fortaz ${ }^{\circledR}, 100 \mathrm{mg} / \mathrm{ml}$, Fresenius Kabi Animal Health) SC q $48 \mathrm{~h}$ for 8 days. Constipation occurred 
postoperatively and resolved 8 days later after the administration of a $12-\mathrm{ml}$ saline enema. The bearded dragon was still doing well, eating well, defecating regularly, and gaining weight 4 months postoperatively.

After excision, the gallbladder was opened, rinsed with saline, and placed in $10 \%$ buffered formaldehyde. The cholelith was stored at $4^{\circ} \mathrm{C}\left(39.2^{\circ} \mathrm{F}\right)$ until submission for composition analysis. The gallbladder was processed routinely for histopathology and stained with H\&E. Histological evaluation by one of the authors (CBL) revealed a mild heterophilic cholecystitis with mild, diffuse, submucosal edema and focal epithelial hyperplasia. These changes were suspected to be induced by chronic irritation from the cholelith. Cholelith analysis revealed carbonates containing a high amount of calcium.

\section{Discussion}

Cholelithiasis, which includes cholecystolithiasis, choledocholithiasis, and cholecystocholedocholithiasis, is one of the most common gastroenterological conditions in humans (Pisano et al., 2019), with a reported prevalence of $10-15 \%$ in adults (Portincasa et al., 2006). The true prevalence of choleliths in bearded dragons is currently unknown. This condition has been reported in seven adult bearded dragons (one individual in Ritzman and Garner [2009]; six of nine individuals in Gimmel et al. [2017]), in addition to the two cases presented herein.

The etiology of cholelithiasis in bearded dragons has yet to be identified. A potential risk factor predisposing bearded dragons raised in captivity to cholelithiasis is their diet (Gimmel et al., 2017). Indeed, a high-protein, high-fat insect-based diet has been previously hypothesized to contribute to the formation of cholecystoliths (Gimmel et al., 2017). Therefore, it is plausible that the high content of mealworms and crickets, representing almost $20 \%$ of the second inland bearded dragon's diet, may have contributed to its cholecystolithiasis. Free-ranging adult bearded dragons are described as balanced insectivorous and herbivorous (MacMillen et al., 1989; Oonincx et al., 2015). The inland bearded dragon of clinical report 1 was fed a diet containing very few insects. Arugula salad, a goitrogenic plant, represented $80 \%$ of this inland bearded dragon's diet. Interestingly, arugula belongs to the Brassicaceae family, members of which contain bioactive phytochemicals such as glucosinolates whose hydrolysis produces thiocyanate (Fahey et al., 2001; Bennett et al., 2006; Azarenko et al., 2014; Cavaiuolo and Ferrante, 2014). Thiocyanate is considered a goitrogenic/antithyroid substance (Chandra, 2010; Lee and Kwon, 2015). A diet rich in Brassicacae leaves can therefore favor secondary nutritional hypothyroidism (Halkier and Gershenzon, 2006), a well-known risk factor for the development of choleliths in humans (Völzke et al., 2005; Laukkarinen et al., 2012). Excessive intake of goitrogenic plant material, such as plants belonging to the Brassicaceae family, has been reported in reptiles as a cause of thyroid hormones deficiencies (Frye and Dutra, 1974; Donoghue, 2005), leading to nutritional secondary hypothyroidism (McArthur and Barrows, 2008). It is unknown whether the inland bearded dragon from clinical report 1 had concurrent nutritional secondary hypothyroidism. In fact, information about the clinical presentation of nutritional secondary hypothyroidism in reptiles is scarce. In chelonians, swelling at the thoracic inlet, lethargy, and dysorexia are reported (Frye and Dutra, 1974) and goiter (an enlarged thyroid gland) can be observed (Donoghue, 2005). In iguanas, hypothyroidism leads to lethargy, weight gain, obesity, decreased rate of growth, and increased docility (Griffin, 2006; Kritchevsky, 2014). Both lethargy and dysorexia were reported in the present case. Because antemortem diagnosis of hypothyroidism in reptiles is challenging with currently available tests (Donoghue, 2005; Leineweber et al., 2019), the hypothesis of nutritional secondary hypothyroidism to explain the formation of a cholelith could not be tested. Reference intervals for thyroid-stimulating hormone concentration are not established, thereby complicating the distinction between sick euthyroid syndrome and hypothyroidism. Avoiding excessive amounts of goitrogen-containing plants has been suggested to prevent secondary nutritional hypothyroidism in reptiles (Kritchevsky, 2014).

Coelomic ultrasonographic examination allowed preoperative diagnosis of cholecystolithiasis in both inland bearded dragons. Most reported cases of cholelithiasis in bearded dragons were diagnosed perioperatively (Ritzman and Garner, 2009; Gimmel et al., 2017), whereas only one case of symptomatic cholelithiasis was diagnosed by ultrasound (Gimmel et al., 2017). In the two cases presented here, the ultrasonographic appearance of the gallbladder was very similar to descriptions of an unaffected gallbladder available in the literature and contained intraluminal debris (Bucy et al., 2015). However, in both cases, the gallbladder was three times larger (approximately $1.5 \mathrm{~cm} \times 3 \mathrm{~cm}$ vs. 0.5 $\mathrm{cm} \times 1 \mathrm{~cm}$ ) than normal (Wachsmann, 2010). Based on this information, a presumptive diagnosis of cholecystolithiasis was made. As such, cholecystolithiasis may be underdiagnosed in adult bearded dragons, as suggested previously (Ritzman and Garner, 2009; Gimmel et al., 2017), especially if gallbladder diameter is not measured during ultrasonographic examination. Radiographic examination failed to identify cholelithiasis preoperatively in both cases presented here, similar to previous reports (Ritzman and Garner, 2009; Gimmel et al., 2017). Indeed, the gallbladder per se or a gallbladder containing a cholelith with or without mineral content cannot be identified by standard radiography in this species, especially with radiographic equipment commonly used for dogs and cats (Wachsmann, 2010). It is unknown whether other radiographic systems, such as those used for mammography in women, would provide better sensitivity. Thus, cholelithiasis cannot be excluded based on the absence of a mineralized opacity in the cranial coelomic region of a bearded dragon on radiography. Biochemistry and hematology results obtained in the second case were consistent with nonspecific inflammation. Of note, hyperglycemia was only obtained via a glucometer in the first case; however, this test is not validated in bearded dragons and was elected 
only due to financial constraints. Hyperglycemia diagnosed using a glucometer overestimated true hyperglycemia in green sea turtles (Chelonia mydas) in a recent report (Perrault et al., 2017). The hyperglycemia diagnosed in this case was considered inconsistent with a somatostatinoma.

Cholecystectomy was elected in both of our inland bearded dragons to surgically manage cholecystolithiasis. In bearded dragons, surgical management of cholecystolithiasis has been previously reported in three individuals, although description of the surgical procedure was not included for any of the individuals. In our two inland bearded dragons, cholecystectomy resulted in a favorable outcome, and both individuals are still doing well 4 and 7 months postsurgery, respectively. In the first reported case, cholecystolithiasis was diagnosed during exploratory coeliotomy. The individual was reportedly still doing well $1 \mathrm{yr}$ after cholecystostomy. Unfortunately, to our knowledge, this case has not been published in a peer-reviewed journal and the surgical technique was not described in detail (Ritzman and Garner, 2009). The second case was diagnosed with cholecystolithiasis during ultrasonographic examination (Gimmel et al., 2017). The surgical method used to remove the cholelith was not described in the report. A favorable outcome was reported, but the followup duration was not mentioned. In the last case, cholecystolithiasis was discovered during surgical management of intestinal constipation (Gimmel et al., 2017). Cholecystectomy was performed and a favorable outcome was reported, but the follow-up duration was not mentioned. In human medicine, early cholecystectomy is considered the gold standard treatment of symptomatic cholecystolithiasis, especially for patients with acute cholecystitis (Tazuma et al., 2017). Indeed, when cholecystectomy is not performed during the admission visit for acute calculous cholelithiasis, mortality in elderly patients, and probability of cholelithiasis-related readmission rates (Riall et al., 2010; Loftus et al., 2017), are significantly higher than in those patients undergoing surgery during the same admission. Also, in a meta-analysis, high death rates and cholelithiasis-related complications were reported in patients with preserved gallbladders (McAlister et al., 2007). In cats with obstructive cholelithiasis, cholecystectomy, cholecystostomy, and biliary derivation are reported; cholecystectomy appears to have low morbidity and good clinical outcome (Eich and Ludwig, 2002).

Antibiotics were administered peri- and postoperatively in the cases reported here because an infectious etiology could not be ruled out initially and to prevent postoperative infections. In human medicine, prophylactic antibiotic administration significantly decreases postoperative infection after surgical cholecystectomy (Lippert and Gastinger, 1998). Perioperative cephalosporins are recommended for surgical interventions involving the biliary tract and in case of bile spillage (Bratzler et al., 2013). Although pharmacokinetic information is available about ceftazidime in reptiles (Lawrence et al., 1984), perioperative use other $\beta$-lactam antibiotics may be sufficient as illustrated in the first case of this report. In retrospect, it is possible that prolonged postoperative antibiotics were not necessary in these cases as no biliary tract infection was noted on histology.

To conclude, cholecystolithiasis should be included in the differential diagnosis of cranial coelomic masses in bearded dragons. Ultrasonography proved to be very useful for the diagnosis of cholecystolithiasis in our two inland bearded dragons, especially size measurements. Total cholecystectomy rather than cholecystostomy was preferred based on ultrasonographic distension (clinical report 1), gallbladder wall thickness, and adhesion to the liver during surgery (clinical report 2). The surgical procedure led to favorable outcomes in both inland bearded dragons presented here. Diversification of vegetables in inland bearded dragons' diet should be encouraged pending more research on cholelithiasis etiology in this species.

Acknowledgements: The authors thank Andrew Moore, MS (Manager of the Diagnostics Unit, Urolith Centre of the University of Guelph, Guelph, ON, Canada) for analyzing the choleliths.

\section{Literature Cited}

Azarenko O, Jordan MA, Wilson L. 2014. Erucin, the major isothiocyanate in arugula (Eruca sativa), inhibits proliferation of MCF7 tumor cells by suppressing microtubule dynamics. PLoS ONE, 9(6):e100599.

Bennett RN, Rosa EAS, Mellon FA, Kroon PA. 2006. Ontogenic profiling of glucosinolates, flavonoids, and other secondary metabolites in Eruca sativa (salad rocket), Diplotaxis erucoides (wall rocket), Diplotaxis tenuifolia (wild rocket), and Bunias orientalis (turkish rocket). J Agric Food Chem, 54(11):4005-4015.

Bratzler DW, Dellinger EP, Olsen KM, Perl TM, Auwaerter PG, Bolon MK, Fish DN, Napolitano LM, Sawyer RG, Slain D, Steinberg JP, Weinstein RA. 2013. Clinical practice guidelines for antimicrobial prophylaxis in surgery. Surg Infect, 14(1):73-156.

Bucy DS, Guzman DS-M, Zwingenberger AL. 2015. Ultrasonographic anatomy of bearded dragons (Pogona vitticeps). J Am Vet Med Assoc, 246(8):868-876.

Cavaiuolo M, Ferrante A. 2014. Nitrates and glucosinolates as strong determinants of the nutritional quality in rocket leafy salads. Nutrients, 6(4):1519-1538.

Chandra AK. 2010. Goitrogen in food: cyanogenic and flavonoids containing plant foods in the development of goiter. In Watson R, Preedy, V (eds): Bioactive Foods in Promoting Health. Elsevier, Philadelphia, PA:691-716.

Divers SJ. 2019. Hepatology. In Divers SJ, Stahl SJ (eds): Mader's Reptile and Amphibian Medicine and Surgery. Elsevier, St. Louis, MO:649-668.

Donoghue S. 2005. Nutrition, In Mader DR, Reptile and Amphibian Medicine and Surgery, Elsevier, Philadelphia, PA: 251-298.

Eich CS, Ludwig LL. 2002. The surgical treatment of cholelithiasis in cats: a study of nine cases. J Am Anim Hosp Assoc, 38(3):290-296.

Ellman MM. 1997. Hematology and plasma chemistry of the inland bearded dragon, Pogona vitticeps. Bull Assoc Reptil Amphib Vet, 7(4):10-12. 
Fahey JW, Zalcmann AT, Talalay P. 2001. The chemical diversity and distribution of glucosinolates and isothiocyanates among plants. Phytochemistry, 56(1):5-51.

Frye F, Dutra F. 1974. Hypothyroidism in turtles and tortoises. Vet Med Small Anim Clin, 69(8):990-993.

Gimmel A, Kempf H, Öfner S, Müller D, Liesegang A. 2017. Cholelithiasis in adult bearded dragons: retrospective study of nine adult bearded dragons (Pogona vitticeps) with cholelithiasis between 2013 and 2015 in southern Germany. J Anim Physiol Anim Nutr, 101:(Suppl 1):122-126.

Grant A, Neuberger J. 1999. Guidelines on the use of liver biopsy in clinical practice. Gut, 45(Suppl. 4):IV1-IV11.

Griffin C. 2006. Possible thyroid hyperplasia in a green iguana (Iguana iguana). Proc ARAV:38.

Griswold WG. 2001. Hepatocellular carcinoma with associated hyperglycemia in an inland bearded dragon, Pogona vitticeps. Proc ARAV:227-231.

Halkier BA, Gershenzon J. 2006. Biology and biochemistry of glucosinolates. Annu Rev Plant Biol, 57:303-333.

Haslewood GAD. 1967. Bile salt evolution. J Lipid Res, 8(6):535-550.

Hernandez-Divers SJ, Cooper JE. 2005. Hepatic lipidosis, In Mader DR, Reptile and Amphibian Medicine and Surgery, Elsevier, Philadelphia, PA: 806-813.

Jakab C, Rusvai M, Szabó Z, Gálfi P, Marosán M, Kulka J, Gál J. 2011. Claudin-7-positive synchronous spontaneous intrahepatic cholangiocarcinoma, adenocarcinoma and adenomas of the gallbladder in a bearded dragon (Pogona vitticeps). Acta Vet Hung, 59(1):99-112.

Klaphake E, Gibbons P, Sladky K, Carpenter J. 2018. Reptiles. In Carpenter JW (ed): Exotic Animal Formulary. 4th ed. Elsevier, St. Louis, MO:124-125.

Kritchevsky JS. 2014. Hypothyroidism in other species. In Rand J (ed): Clinical Endocrinology of Companion Animals. John Wiley \& Sons, Philadelphia, PA:278-290.

Laukkarinen J, Sand J, Nordback I. 2012. The underlying mechanisms: how hypothyroidism affects the formation of common bile duct stones - a review. HPB Surg, 2012:1-7.

Lawrence K, Muggleton PW, Needham JR. 1984. Preliminary study on the use of ceftazidime, a broad spectrum cephalosporin antibiotic, in snakes. Res Vet Sci, 36(1):1620.

Lee J, Kwon H. 2015. In vitro metabolic conversion of the organic breakdown products of glucosinolate to goitrogenic thiocyanate anion. J Sci Food Agric, 95(11):2244-2251.

Leineweber C, Öfner S, Mathes K, Marschang R, Stöhr A. 2019. Season and sex specific thyroid hormone levels in different European tortoise species (Testudo spp.). Proceedings of the Zoo and Wildlife Health Conference 2019; 12-15 Jun, Kolmärden, Sweden:28.

Lippert H, Gastinger J. 1998. Antimicrobial prophylaxis in laparoscopic and conventional cholecystectomy. Chemotherapy, 44(5):355-363.

Loftus TJ, Collins EM, Dessaigne CG, Himmler AN, Mohr AM, Thomas RM, Hobson CE, Sarosi GA, Zingarelli WJ. 2017. Percutaneous cholecystostomy: prognostic factors and comparison to cholecystectomy. Surg Endosc, 31(11):45684575.

MacMillen RE, Augee ML, Ellis BA. 1989. Thermal ecology and diet of some xerophilous lizards from western New South Wales. J Arid Environ, 16(2):193-201.
Mans C. 2013. Clinical update on diagnosis and management of disorders of the digestive system of reptiles. J Exot Pet Med, 22(2):141-162.

McAlister VC, Davenport E, Renouf E. 2007. Cholecystectomy deferral in patients with endoscopic sphincterotomy. Cochrane Database Syst Rev, 4:CD006233.

McArthur S, Barrows M. 2008. Nutrition. In McArthur S, Wilkinson R, Meyer J (eds): Medicine and Surgery of Tortoises and Turtles. John Wiley \& Sons, Philadelphia, PA:73-85.

Oonincx DGAB, van Leeuwen JP, Hendriks WH, van der Poel AFB. 2015. The diet of free-roaming Australian central bearded dragons (Pogona vitticeps). Zoo Biol, 34(3):271277.

Perrault JR, Bresette MJ, Mott CR, Stacy NI. 2017. Comparison of whole blood and plasma glucose concentrations in green turtles (Chelonia mydas) determined using a glucometer and a dry chemistry analyzer. J Wildl Dis, 54(1):196-199.

Pisano M, Ceresoli M, Cimbanassi S, Gurusamy K, Coccolini F, Borzellino G, Costa G, Allievi N, Amato B, Boerma D, Calcagno P, Campanati L. 2019. 2017 WSES and SICG guidelines on acute calcolous cholecystitis in elderly population. World J Emerg Surg, 14:10.

Portincasa P, Moschetta A, Palasciano G. 2006. Cholesterol gallstone disease. Lancet Lond Engl, 3689531:230-239.

Riall TS, Zhang D, Townsend CM, Kuo Y-F, Goodwin JS. 2010. Failure to perform cholecystectomy for acute cholecystitis in elderly patients is associated with increased morbidity, mortality, and cost. J Am Coll Surg, 210(5):668-679.

Ritter JM, Garner MM, Chilton JA, Jacobson ER, Kiupel M. 2009. Gastric neuroendocrine carcinomas in bearded dragons (Pogona vitticeps). Vet Pathol, 46(6):1109-1116.

Ritzman TK, Garner MM. 2009. Cholelithiasis and surgical cholelith removal in a bearded dragon (Pogona vitticeps), Proc ARAV:117.

Sladky KK, Mans C. 2019. Analgesia. In Divers SJ, Stahl SJ (eds): Mader's Reptile and Amphibian Medicine and Surgery. Elsevier, St. Louis, MO:465-474

Sladky KK, Kinney ME, Johnson SM. 2008. Analgesic efficacy of butorphanol and morphine in bearded dragons and corn snakes. J Am Vet Med Assoc, 233(2):267-273.

Tamukai K, Takami Y, Akabane Y, Kanazawa Y, Une Y. 2011. Plasma biochemical reference values in clinically healthy captive bearded dragons (Pogona vitticeps) and the effects of sex and season. Vet Clin Pathol, 40(3):368-373.

Tazuma S, Unno M, Igarashi Y, Inui K, Uchiyama K, Kai M, Tsuyuguchi T, Maguchi H, Mori T, Yamaguchi K, Ryozawa S, Nimura Y, Fujita N, Kubota K, Shoda J, Tabata M, Mine T, Sugano K, Watanabe M, Shimosegawa T. 2017. Evidence-based clinical practice guidelines for cholelithiasis 2016. J Gastroenterol, 52(3):276-300.

Völzke H, Robinson DM, John U. 2005. Association between thyroid function and gallstone disease. World J Gastroenterol, 11(35):5530-5534.

Wachsmann S. 2010. Ultraschalluntersuchungen bei Bartagamen (Pogona vitticeps) unter Berücksichtigung klinischer, röntgenologischer und labordiagnostischer Parameter. 1. Aufl ed. DVG, Gießen, Germany. 